\title{
Berinde-Borcut tripled fixed point theorem in partially ordered (intuitionistic) fuzzy normed spaces
}

\author{
Poom Kumam ${ }^{1}$, Juan Martínez-Moreno ${ }^{2 *}$, Antonio-Francisco Roldán-López-de-Hierro² and \\ Concepción Roldán-López-de-Hierro ${ }^{3}$
}

*Correspondence:

jmmoreno@ujaen.es

${ }^{2}$ Department of Mathematics,

University of Jaén, Campus Las Lagunillas, s/n, Jaén, 23071, Spain

Full list of author information is

available at the end of the article

\begin{abstract}
In this paper, we prove some tripled fixed point theorems in fuzzy normed spaces. Our results improve and restate the proof lines of the main results given in the paper (Abbas et al. in Fixed Point Theory Appl. 2012:187, 2012).
\end{abstract}

Keywords: fuzzy metric space; tripled fixed point; intuitionistic space

\section{Introduction}

Once the notion of coupled fixed point was given by Gnana Bhaskar and Lakshmikantham in [1], the theory of multidimensional fixed points has attracted much attention (see, for instance, [2-8]), specially in the tripled case (see [9-17]).

Recently, many authors have shown the existence of tripled fixed points and common tripled fixed points for some contractions in cone metric spaces, partially ordered metric spaces, fuzzy metric spaces, fuzzy normed spaces, intuitionistic fuzzy normed spaces and others. Especially in [18], Abbas et al. proved some tripled fixed point theorem for contractive mappings in partially complete intuitionistic fuzzy normed spaces. But the authors found some mistakes in the proof lines of their main result. In this paper we give a corrected version of the main theorem.

A $t$-norm (resp., a $t$-conorm) is a mapping $*:[0,1]^{2} \rightarrow[0,1]$ (resp., $\left.\diamond:[0,1]^{2} \rightarrow[0,1]\right)$ that is associative, commutative, and non-decreasing in both arguments and has 1 (resp., $0)$ as identity.

Definition $1([19,20])$ For any $a \in[0,1]$, let the sequence $\left\{*^{n} a\right\}_{n=1}^{\infty}$ be defined by $*^{1} a=a$ and $*^{n} a=\left(*^{n-1} a\right) * a$. Then a $t$-norm $*$ is said to be of $H$-type if the sequence $\left\{*^{n} a\right\}_{n=1}^{\infty}$ is equicontinuous at $a=1$.

Definition 2 A fuzzy normed space (briefly, FNS) is a triple $(X, \mu, *)$, where $X$ is a vector space, $*$ is a continuous $t$-norm and $\mu: X \times(0, \infty) \rightarrow[0,1]$ is a fuzzy set such that, for all $x, y \in X$ and $t, s>0$,

(F1) $\mu(x, t)>0$;

(F2) $\mu(x, t)=1$ for all $t>0$ if and only if $x=0$;

(F3) $\mu(\alpha x, t)=\mu\left(x, \frac{t}{|\alpha|}\right)$ for all $\alpha \neq 0$;

Q2014 Kumam et al: licensee Springer. This is an Open Access article distributed under the terms of the Creative Commons Attribution License (http://creativecommons.org/licenses/by/2.0), which permits unrestricted use, distribution, and reproduction in any medium, provided the original work is properly cited. 
(F4) $\mu(x, t) * \mu(y, s) \leq \mu(x+y, t+s)$;

(F5) $\mu(x, \cdot):(0, \infty) \rightarrow[0,1]$ is continuous;

(F6) $\lim _{t \rightarrow \infty} \mu(x, t)=1$ and $\lim _{t \rightarrow 0} \mu(x, t)=0$.

Using the continuous $t$-norms and $t$-conorms, Saadati and Park [21] introduced the concept of an intuitionistic fuzzy normed space.

Definition 3 ([21, 22]) An intuitionistic fuzzy normed space (briefly, IFNS) is a 5-tuple $(X, \mu, v, *, \diamond)$ where $X$ is a vector space, $*$ is a continuous $t$-norm, $\diamond$ is a continuous $t$ conorm and $\mu, v: X \times(0, \infty) \rightarrow[0,1]$ are fuzzy sets such that, for all $x, y \in X$ and $t, s>0$,

(IF1) $\mu(x, t)+v(x, t) \leq 1$

(IF2) $\mu(x, t)>0$ and $v(x, t)<1$;

(IF3) $\mu(x, t)=1$ for all $t>0$ if and only if $x=0$ if and only if $v(x, t)=0$ for all $t>0$;

(IF4) $\mu(\alpha x, t)=\mu\left(x, \frac{t}{|\alpha|}\right)$ and $\nu(\alpha x, t)=v\left(x, \frac{t}{|\alpha|}\right)$ for all $\alpha \neq 0$;

(IF5) $\mu(x, t) * \mu(y, s) \leq \mu(x+y, t+s)$ and $v(x, t) \diamond v(y, s) \geq v(x+y, t+s)$;

(IF6) $\mu(x, \cdot), v(x, \cdot):(0, \infty) \rightarrow[0,1]$ are continuous;

(IF7) $\lim _{t \rightarrow \infty} \mu(x, t)=1=\lim _{t \rightarrow 0} v(x, t)$ and $\lim _{t \rightarrow 0} \mu(x, t)=0=\lim _{t \rightarrow \infty} v(x, t)$.

Obviously, if $(X, \mu, \nu, *, \diamond)$ is a IFNS, then $(X, \mu, *)$ is a FNS. We refer to this space as its support.

Lemma $4 \mu(x, \cdot)$ is a non-decreasing function on $(0, \infty)$ and $v(x, \cdot)$ is a non-increasing function on $(0, \infty)$.

Some properties and examples of IFNS and the concepts of convergence and a Cauchy sequence in IFNS are given in [21].

Definition 5 Let $(X, \mu, v, *, \diamond)$ be an IFNS.

(1) A sequence $\left\{x_{n}\right\} \subset X$ is called a Cauchy sequence if, for any $\epsilon>0$ and $t>0$, there exists $n_{0} \in \mathbb{N}$ such that $\mu\left(x_{n}-x_{m}, t\right)>1-\epsilon$ and $v\left(x_{n}-x_{m}, t\right)<\epsilon$ for all $n, m \geq n_{0}$.

(2) A sequence $\left\{x_{n}\right\} \subset X$ is said to be convergent to a point $x \in X$, denoted by $x_{n} \rightarrow x$ or by $\lim _{n \rightarrow \infty} x_{n}=x$, if, for any $\epsilon>0$ and $t>0$, there exists $n_{0} \in \mathbb{N}$ such that $\mu\left(x_{n}-x, t\right)>1-\epsilon$ and $v\left(x_{n}-x, t\right)<\epsilon$ for all $n \geq n_{0}$.

(3) An IFNS in which every Cauchy sequence is convergent is said to be complete.

Definition 6 ([7]) Let $F: X^{3} \rightarrow X$ and $g: X \rightarrow X$ be two mappings.

- We say that $F$ and $g$ are commuting if $g F(x, y, z)=F(g x, g y, g z)$ for all $x, y, z \in X$.

- A point $(x, y, z) \in X^{3}$ is called a tripled coincidence point of the mappings $F$ and $g$ if $F(x, y, z)=g x, F(y, x, y)=g y$ and $F(z, y, x)=g z$. If $g$ is the identity, $(x, y, z)$ is called a tripled fixed point of $F$.

- If $(X, \sqsubseteq)$ is a partially ordered set, then $F$ is said to have the mixed $g$-monotone property if it verifies the following properties:

$$
\begin{aligned}
& x_{1}, x_{2} \in X, \quad g x_{1} \sqsubseteq g x_{2} \quad \Longrightarrow \quad F\left(x_{1}, y, z\right) \sqsubseteq F\left(x_{2}, y, z\right), \quad \forall y \in X, \\
& y_{1}, y_{2} \in X, \quad g y_{1} \sqsubseteq g y_{2} \quad \Longrightarrow \quad F\left(x, y_{1}, z\right) \sqsupseteq F\left(x, y_{2}, z\right), \quad \forall x \in X, \\
& z_{1}, z_{2} \in X, \quad g z_{1} \sqsubseteq g z_{2} \quad \Longrightarrow \quad F\left(x, y, z_{1}\right) \sqsubseteq F\left(x, y, z_{2}\right), \quad \forall x \in X .
\end{aligned}
$$


If $g$ is the identity mapping, then $F$ is said to have the mixed monotone property.

- If $(X, \sqsubseteq)$ is a partially ordered set, then $X$ is said to have the sequential g-monotone property if it verifies the following properties:

(B1) If $\left\{x_{n}\right\}$ is a non-decreasing sequence and $\lim _{n \rightarrow \infty} x_{n}=x$, then $g x_{n} \sqsubseteq g x$ for all $n \in \mathbb{N}$.

(B2) If $\left\{x_{n}\right\}$ is a non-increasing sequence and $\lim _{n \rightarrow \infty} y_{n}=y$, then $g y_{n} \sqsupseteq g y$ for all $n \in \mathbb{N}$.

If $g$ is the identity mapping, then $X$ is said to have the sequential monotone property.

Definition 7 Let $X$ and $Y$ be two IFNS. A function $f: X \rightarrow Y$ is said to be continuous at a point $x_{0} \in X$ if, for any sequence $\left\{x_{n}\right\}$ in $X$ converging to $x_{0}$, the sequence $\left\{f\left(x_{n}\right)\right\}$ in $Y$ converges to $f\left(x_{0}\right)$. If $f$ is continuous at each $x \in X$, then $f$ is said to be continuous on $X$.

The following lemma proved by Haghi et al. [23] is useful for our main results:

Lemma 8 Let $X$ be a nonempty set and $g: X \rightarrow X$ be a mapping. Then there exists a subset $E \subset X$ such that $g(E)=g(X)$ and $g: E \rightarrow X$ is one-to-one.

Definition 9 Let $(X, \mu, \nu, *, \diamond)$ be an IFNS. The pair $(\mu, \nu)$ is said to satisfy the $n$-property on $X \times(0, \infty)$ if $\lim _{n \rightarrow \infty}\left[\mu\left(x, k^{n} t\right)\right]^{n^{p}}=1$ and $\lim _{n \rightarrow \infty}\left[v\left(x, k^{n} t\right)\right]^{n^{p}}=0$ whenever $x \in X, k>1$ and $p>0$.

In order to state our results, we recall the main result given in [18].

Theorem 10 (Abbas et al., Theorem 2.2) Let $(X, \sqsubseteq)$ be a partially ordered set and suppose that $a \diamond a=a, a b \leq a * b$ for all $a, b \in[0,1]$. Let $(X, \mu, v, *, \diamond)$ be a complete IFNS such that $(\mu, v)$ has the n-property. Let $F: X \times X \times X \rightarrow X$ and $g: X \rightarrow X$ be two mappings such that $F$ has the mixed g-monotone property and

$$
\begin{aligned}
& \mu(F(x, y, z)-F(u, v, w), k t) \geq \mu(g x-g u, t) * \mu(g y-g v, t) * \mu(g z-g w, t), \\
& v(F(x, y, z)-F(u, v, w), k t) \leq v(g x-g u, t) \diamond v(g y-g v, t) \diamond v(g z-g w, t),
\end{aligned}
$$

for which $g x \sqsubseteq g u$ and $g y \sqsupseteq g v$ and $g z \sqsubseteq g w$, where $0<k<1$. Suppose either

(a) $F$ is continuous or

(b) $X$ has the sequential g-monotone property.

If there exist $x_{0}, y_{0}, z_{0} \in X$ such that $g x_{0} \sqsubseteq F\left(x_{0}, y_{0}, z_{0}\right), g y_{0} \sqsupseteq F\left(y_{0}, x_{0}, y_{0}\right)$ and $g z_{0} \sqsubseteq$ $F\left(z_{0}, y_{0}, x_{0}\right)$, then $F$ and $g$ have a tripled coincidence point.

\section{Comments and revised tripled fixed point theorem}

Firstly, we show that the conditions of Theorem 10 are inadequate and, further, the proof lines of Theorem 10 are not correct. We also would like to point out that the results in [18] can be corrected under the appropriate conditions on the $t$-norm and the FNS. The proof lines of Theorem 10 are not correct (see pp.7 and 8):

$$
\mu\left(x_{n}-x_{m}, t\right) \geq\left[\mu\left(x_{0}-x_{1},(1-k) \frac{t}{k^{n}}\right)\right]^{m} \geq\left[\mu\left(x_{0}-x_{1},(1-k) \frac{t}{k^{n}}\right)\right]^{n^{p}} \rightarrow 1,
$$


where $p>0$ such that $m<n^{p}$. Hence the sequence $\left\{x_{n}\right\}$ is a Cauchy sequence. This is not correct since the same $p$ would not be valid for all positive integers $m>n \geq n_{0}$. For example, let $(X,\|\cdot\|)$ be an ordinary normed space, define $\mu(x, t)=\frac{t}{t+\|x\|}$ for any $x \in X$ and $t>0$ and $a * b=a b$ for all $a, b \in[0,1]$. Then $\left(X, \mu, 1-\mu, *, *^{\prime}\right)$ is an IFNS. If $k=1 / 2$ and $m=2^{n}$, we have

$$
\left[\mu\left(x_{0}-x_{1},(1-k) \frac{t}{k^{n}}\right)\right]^{m}=\left[\frac{2^{n-1} t}{2^{n-1} t+\left\|x_{0}-x_{1}\right\|}\right]^{2^{n}} \rightarrow \mathrm{e}^{-\frac{2\left\|x_{0}-x_{1}\right\|}{t}}<1 .
$$

Now, by replacing in Theorem 10 the hypothesis that $\mu$ satisfies the $n$-property with the one that the $t$-norm is of $H$-type, we state and prove a tripled fixed point theorem as a modification.

Theorem 11 Let $(X, \sqsubseteq)$ be a partially ordered set and $(X, \mu, *)$ be a complete FNS such that $*$ is of $H$-type and $a * a \geq$ a for all $a \in[0,1]$. Let $k \in(0,1)$ be a number and $F: X \times X \times X \rightarrow$ $X$ be mapping such that $F$ has the mixed monotone property and

$$
\mu(F(x, y, z)-F(u, v, w), k t) \geq \mu(x-u, t) * \mu(y-v, t) * \mu(z-w, t)
$$

for which $x \sqsubseteq u, y \sqsupseteq v$ and $z \sqsubseteq w$. Suppose that either:

(a) $F$ is continuous or

(b) $X$ has the sequential monotone property.

If there exist $x_{0}, y_{0}, z_{0} \in X$ such that $x_{0} \sqsubseteq F\left(x_{0}, y_{0}, z_{0}\right), y_{0} \sqsupseteq F\left(y_{0}, x_{0}, y_{0}\right)$ and $z_{0} \sqsubseteq F\left(z_{0}, y_{0}\right.$, $\left.x_{0}\right)$, then $F$ has a tripled fixed point. Furthermore, if $x_{0}$ and $y_{0}$ are comparable, then $x=y$, that is, $x=F(x, x)$.

Proof As in [18] starting with $x_{0}, y_{0}, z_{0} \in X$ such that $x_{0} \sqsubseteq F\left(x_{0}, y_{0}, z_{0}\right), y_{0} \sqsupseteq F\left(y_{0}, x_{0}, y_{0}\right)$ and $z_{0} \sqsubseteq F\left(z_{0}, y_{0}, x_{0}\right)$, one can define inductively three sequences $\left\{x_{n}\right\},\left\{y_{n}\right\},\left\{z_{n}\right\} \subset X$ such that $x_{n+1}=F\left(x_{n}, y_{n}, z_{n}\right), y_{n+1}=F\left(y_{n}, x_{n}, y_{n}\right)$ and $z_{n+1}=F\left(z_{n}, y_{n}, x_{n}\right)$.

Define

$$
\delta_{n}(t)=\mu\left(x_{n}-x_{n+1}, t\right) * \mu\left(y_{n}-y_{n+1}, t\right) * \mu\left(z_{n}-z_{n+1}, t\right) .
$$

Continuing as in [18], we have

$$
\begin{aligned}
& \mu\left(x_{n}-x_{n+1}, k t\right) \geq \delta_{n-1}(t), \quad \mu\left(y_{n}-y_{n+1}, k t\right) \geq \delta_{n-1}(t) \quad \text { and } \\
& \mu\left(z_{n}-z_{n+1}, k t\right) \geq \delta_{n-1}(t) * \delta_{n-1}(t) .
\end{aligned}
$$

Since $a * a \geq a$ for all $a \in[0,1]$, it follows that

$$
\delta_{n}(k t)=\mu\left(x_{n}-x_{n+1}, k t\right) * \mu\left(y_{n}-y_{n+1}, k t\right) * \mu\left(z_{n}-z_{n+1}, k t\right) \geq \delta_{n-1}(t) .
$$

This implies that

$$
1 \geq \delta_{n}(t) \geq \delta_{n-1}\left(\frac{t}{k}\right) \geq \delta_{n-2}\left(\frac{t}{k^{2}}\right) \geq \cdots \geq \delta_{0}\left(\frac{t}{k^{n}}\right) .
$$

Since $\lim _{n \rightarrow \infty} \delta_{0}\left(\frac{t}{k^{n}}\right)=1$ for all $t>0$, we have $\lim _{n \rightarrow \infty} \delta_{n}(t)=1$ for all $t>0$. 
Now, we claim that, for any $p \geq 1$ and $n \geq 1$,

$$
\begin{aligned}
& \mu\left(x_{n}-x_{n+p}, t\right) \geq *^{p} \delta_{n-1}(t-k t), \\
& \mu\left(y_{n}-y_{n+p}, t\right) \geq *^{p} \delta_{n-1}(t-k t), \quad \text { and } \\
& \mu\left(z_{n}-z_{n+p}, t\right) \geq *^{p} \delta_{n-1}(t-k t) .
\end{aligned}
$$

In fact, it is obvious for $p=1$ by (2), $a * a \geq a$ and Lemma 4 since $t / k \geq t-k t$ and $\delta_{n-1}$ is non-decreasing. Assume that (3) holds for some $p \geq 1$. By (2), we have

$$
\mu\left(x_{n}-x_{n+1}, t\right) \geq \mu\left(x_{n}-x_{n+1}, k t\right) \geq \delta_{n-1}(t)
$$

and so

$$
\mu\left(x_{n}-x_{n+1}, t-k t\right) \geq \delta_{n-1}(t-k t) .
$$

Thus, from (1), (3) and $a * a \geq a$, we have

$$
\begin{aligned}
\mu\left(x_{n+1}-x_{n+p+1}, k t\right) & \geq \mu\left(x_{n}-x_{n+p}, t\right) * \mu\left(y_{n}-y_{n+p}, t\right) * \mu\left(z_{n}-z_{n+p}, t\right) \\
& \geq *^{p} \delta_{n-1}(t-k t) .
\end{aligned}
$$

Hence, by the monotonicity of the $t$-norm $*$, we have

$$
\begin{aligned}
\mu\left(x_{n}-x_{n+p+1}, t\right) & =\mu\left(x_{n}-x_{n+p+1}, t-k t+k t\right) \\
& \geq \mu\left(x_{n}-x_{n+1}, t-k t\right) * \mu\left(x_{n+1}-x_{n+p+1}, k t\right) \\
& \geq \delta_{n-1}(t-k t) *\left(*^{p} \delta_{n-1}(t-k t)\right)=*^{p+1} \delta_{n-1}(t-k t) .
\end{aligned}
$$

Similarly, we have

$$
\begin{aligned}
& \mu\left(y_{n+1}-y_{n+p+1}, k t\right) \geq *^{p+1} \delta_{n-1}(t-k t) \quad \text { and } \\
& \mu\left(z_{n+1}-z_{n+p+1}, k t\right) \geq *^{p+1} \delta_{n-1}(t-k t) .
\end{aligned}
$$

Therefore, by induction, (3) holds for all $p \geq 1$. Suppose that $t>0$ and $\epsilon \in(0,1]$ are given. By hypothesis, since $*$ is a $t$-norm of $H$-type, there exists $0<\eta<1$ such that $*^{p}(a)>1-\epsilon$ for all $a \in(1-\eta, 1]$ and $p \geq 1$. Since $\lim _{n \rightarrow \infty} \delta_{n}(t)=1$, there exists $n_{0}$ such that $\delta_{n}(t-k t)>1-\eta$ for all $n \geq n_{0}$. Hence, from (3), we get

$$
\mu\left(x_{n}-x_{n+p}, t\right)>1-\epsilon, \quad \mu\left(y_{n}-y_{n+p}, t\right)>1-\epsilon, \quad \mu\left(z_{n}-z_{n+p}, t\right)>1-\epsilon, \quad \forall n \geq n_{0} .
$$

Therefore, $\left\{x_{n}\right\},\left\{y_{n}\right\}$ and $\left\{z_{n}\right\}$ are Cauchy sequences. We can continue as in [18] to complete the proof.

Theorem 12 Let $(X, \sqsubseteq)$ be a partially ordered set and $(X, \mu, *)$ be a complete FNS such that $*$ is of $H$-type and $a * a \geq a$ for all $a \in[0,1]$. Let $k \in(0,1)$ be a number and $F: X \times X \times X \rightarrow$ 
$X$ and $g: X \rightarrow X$ be two mappings such that $F$ has the mixed $g$-monotone property and

$$
\begin{aligned}
& \mu(F(x, y, z)-F(u, v, w), k t) \geq \mu(g x-g u, t) * \mu(g y-g v, t) * \mu(g z-g w, t), \\
& v(F(x, y, z)-F(u, v, w), k t) \leq v(g x-g u, t) \diamond v(g y-g v, t) \diamond v(g z-g w, t),
\end{aligned}
$$

for which $g x \sqsubseteq g u$ and $g y \sqsupseteq g v$ and $g z \sqsubseteq g w$, where $0<k<1$. Suppose either

(a) $F$ is continuous or

(b) $X$ has the sequential $g$-monotone property.

If there exist $x_{0}, y_{0}, z_{0} \in X$ such that $g x_{0} \sqsubseteq F\left(x_{0}, y_{0}, z_{0}\right), g y_{0} \sqsupseteq F\left(y_{0}, x_{0}, y_{0}\right)$ and $g z_{0} \sqsubseteq$ $F\left(z_{0}, y_{0}, x_{0}\right)$, then $F$ and $g$ have a tripled coincidence point.

Proof As in Theorem 2.2 in [18].

\section{Of course, all the results are valid if $X$ is intuitionistic.}

\section{Competing interests}

The authors declare that they have no competing interests.

\section{Authors' contributions}

All authors contributed equally and significantly in writing this paper. All authors read and approved the final manuscript.

\section{Author details}

'Department of Mathematics, Faculty of Science, King Mongkut's University of Technology Thonburi (KMUTT), Bang Mod, Thrung Khru, Bangkok, Thailand. ²Department of Mathematics, University of Jaén, Campus Las Lagunillas, s/n, Jaén, 23071, Spain. ${ }^{3}$ Department of Statistics and Operations Research, University of Granada, Granada, Spain.

\section{Acknowledgements}

The first author was supported by the Higher Education Research Promotion and National Research University Project of Thailand, Office of the Higher Education Commission (Under NRU-CSEC Project No. NRU56000508). The last three authors have been partially supported by Junta de Andalucía, by projects FQM-268, FQM-178 and FQM-235 of the Andalusian CICYE.

Received: 1 October 2013 Accepted: 8 January 2014 Published: 30 Jan 2014

\section{References}

1. Gnana Bhaskar, T, Lakshmikantham, V: Fixed point theorems in partially ordered metric spaces and applications. Nonlinear Anal. 65, 1379-1393 (2006)

2. Berinde, $\mathrm{V}$, Borcut, $\mathrm{M}$ : Tripled fixed point theorems for contractive type mappings in partially ordered metric spaces. Nonlinear Anal. 74, 4889-4897 (2011)

3. Borcut, $M$, Berinde, $\mathrm{V}$ : Tripled coincidence theorems for contractive type mappings in partially ordered metric spaces. Appl. Math. Comput. 218, 5929-5936 (2012)

4. Aydi, H, Karapınar, E, Postolache, M: Tripled coincidence theorems for weak $\varphi$-contractions in partially ordered metric spaces. Fixed Point Theory Appl. 2012, 44 (2012)

5. Karapınar, E, Luong, N: Quadruple fixed point theorems for nonlinear contractions. Comput. Math. Appl. 64, 1839-1848 (2012)

6. Karapınar, E, Berinde, V: Quadruple fixed point theorems for nonlinear contractions in partially ordered metric spaces. Banach J. Math. Anal. 6, 74-89 (2012)

7. Roldán, A, Martínez-Moreno, J, Roldán, C: Multidimensional fixed point theorems in partially ordered complete metric spaces. J. Math. Anal. Appl. 396, 536-545 (2012)

8. Roldán, A, Martínez-Moreno, J, Roldán, C: Multidimensional coincidence point results for compatible mappings in partially ordered fuzzy metric spaces. Fuzzy Sets Syst. (2013). doi:10.1016/j.fss.2013.10.009

9. Aydi, H, Karapınar, E, Shatanawi, W: Tripled fixed point results in generalized metric spaces. J. Appl. Math. 2012, $314279(2012)$

10. Karapınar, E, Aydi, H, Mustafa, Z: Some tripled coincidence point theorems for almost generalized contractions in ordered metric spaces. Tamkang J. Math. 44, 233-251 (2013)

11. Aydi, H, Karapınar, E, Radenovic, S: Tripled coincidence fixed point results for Boyd-Wong and Matkowski type contractions. Rev. R. Acad. Cienc. Exactas Fís. Nat., Ser. a Mat. 107, 339-353 (2013)

12. Aydi, H, Karapınar, E, Shatanawi, W: Tripled common fixed point results for generalized contractions in ordered generalized metric spaces. Fixed Point Theory Appl. 2012, 101 (2012)

13. Aydi, H, Karapınar, E: New Meir-Keeler type tripled fixed point theorems on ordered partial metric spaces. Math. Probl. Eng. 2012, 409872 (2012)

14. Aydi, H, Karapınar, E, Shatanawi, W: Tripled fixed point results in generalized metric spaces. J. Appl. Math. 2012, 314279 (2012) 
15. Abbas, M, Aydi, H, Karapınar, E: Tripled fixed points of multi-valued nonlinear contraction mappings in partially ordered metric spaces. Abstr. Appl. Anal. 2011, 812690 (2011)

16. Aydi, H, Karapınar, E: Tripled coincidence point theorems for a class of contractions in ordered metric spaces. Acta Univ. Apulensis 32, 193-205 (2012)

17. Aydi, H, Karapınar, E: Tripled fixed points in ordered metric spaces. Bull. Math. Anal. Appl. 4, 197-207 (2012)

18. Abbas, M, Ali, B, Sintunaravat, W, Kumam, P: Tripled fixed point and tripled coincidence point theorems in intuitionistic fuzzy normed spaces. Fixed Point Theory Appl. 2012, 187 (2012)

19. Hadžić, O, Pap, E: Fixed Point Theory in Probabilistic Metric Spaces. Kluwer Academic, Dordrecht (2001)

20. Roldán, A, Martínez-Moreno, J, Roldán, C: Tripled fixed point theorem in fuzzy metric spaces and applications. Fixed Point Theory Appl. 2013, 29 (2013)

21. Saadati, R, Park, J: On the intuitionistic fuzzy topological spaces. Chaos Solitons Fractals 27, 231-344 (2006)

22. Roldán, A, Martínez-Moreno, J, Roldán, C: On interrelationships between fuzzy metric structures. Iran. J. Fuzzy Syst. 10 133-150 (2013)

23. Haghi, R, Rezapour, H, Shahzad, N: Some fixed point generalizations are not real generalizations. Nonlinear Anal. 74, 1799-1803 (2011)

10.1186/1029-242X-2014-47

Cite this article as: Kumam et al.: Berinde-Borcut tripled fixed point theorem in partially ordered (intuitionistic) fuzzy normed spaces. Journal of Inequalities and Applications 2014, 2014:47

\section{Submit your manuscript to a SpringerOpen ${ }^{\circ}$ journal and benefit from:}

- Convenient online submission

- Rigorous peer review

- Immediate publication on acceptance

Open access: articles freely available online

High visibility within the field

- Retaining the copyright to your article 